\title{
Sudanese Refugees in Australia: The Impact of Acculturation Stress
}

\author{
Karla Milner and Nigar G. Khawaja \\ Queensland University of Technology, Australia
}

\begin{abstract}
$R^{0}$ efugees from Sudan are the fastest growing community in Australia. Australian mental health professionals have to be prepared to offer services to this ethnic group along with the other mainstream and diverse consumers. In order to offer culturally competent services, these mental health professionals are required to be familiar with this emerging community. As such, a review was undertaken with two main goals. Firstly, the review aimed to educate Australian mental health professionals about the demographics and culture of Sudan, the traumas encountered as a result of the civil war, factors leading to massive exodus and the difficulties of the transit and postmigration phase. Secondly, the review intended to inform Australian mental health professionals about the possible acculturation stress that is manifested in the form of intergeneration and role conflict and marital difficulties. The review highlights limitations on the number of studies addressing acculturation stress of Sudanese refugees and even fewer on the impact it has on relationships. Future research directions are discussed.
\end{abstract}

Keywords: Sudanese, refugees, acculturation

The Sudanese community of more than 20,000 nationwide has been described as 'Australia's fastest growing newly emerging community'. By 2001, Australia had accepted over 8,000 refugees from the Sudan alone (Department of Immigration and Multicultural Affairs [DIMA], 2006), with Sudanese refugees entering Australia mostly under the Special Humanitarian (202) Visa category (Coffey, 2004). By definition, refugees are those who reside outside their country of origin and are unable to return due to 'a well founded fear of being persecuted for reasons of race, religion, nationality, membership of a particular social or political opinion ...' (United Nations High Commission for Refugees [UNHCR], 1951). Refugees who are identified through the UNHCR enter Australia through a governmentsponsored humanitarian program that provides the entrants with initial support in areas of health, social welfare entitlements, accommodation and language training. Alternatively, refugees may be sponsored by a family member or organisation to enter Australia.

These Sudanese refugees entering on humanitarian grounds have encountered traumas frequently in their own homeland (Schweitzer, Melville, Steel, \& Lacherez,
2006). In addition, the period after leaving Sudan and before entering Australia is often very distressing (Khawaja, White, Schweitzer, \& Greenslade, 2008). Such factors have an impact on their mental health and wellbeing (Steel, Silove, Phan, \& Bauman, 2002). Postmigration settlement in a very unfamiliar environment and culture involves complex challenges. According to Professor Babacan (quoted in The Age, Melbourne) a survey completed for a government department in 2006 about Sudanese resettlement indicated that $70 \%$ of Sudanese refugees received no information about Australia before arriving, resulting in considerable difficulty with settlement (Jackson, 2007; United Nations Development Programme [UNDP], 2008). Moreover, difficulties with integrating into Australian society have been reported due to literacy and language issues, problems within the educational and vocational sector and violence within the community (Alexander, 2008; Thlabano \& Schweitzer, 2007). A successful settlement involves acculturation, which is a result of the interaction between the host and the new community (Berry, 1997). Generally, the new arrivals go through a process of examining their original values and 
cultural beliefs and modifying them as a result of integrating within the host culture (Sam \& Berry, 2006). The newly arrived vary in acculturation and often this process leads to stress (Berry, 1997). The stress may emerge in various forms and can impede the adjustment (Poppitt \& Frey, 2007). Thus, a combination of premigration traumas, transit and postmigration difficulties and acculturation stress can affect the psychological wellbeing and mental health of the refugees.

As a part of their professional practice mental health professionals often have to counsel people who are refugees (Yakushko, Watson, \& Thompson, 2008). Australian mental health professionals have to be prepared for this new emerging community (Tempany, 2009). They have to develop a deep understanding of this group's background, difficulties and dilemmas. Thus, the goals of this review are twofold. Firstly, it informs Australian mental health professionals about the culture and demographics of Sudan, the war-related conflicts, traumas encountered as a result of the war, transit and postmigration difficulties. Secondly, the literature is reviewed to familiarise mental health professionals about the acculturation process and the resulting stress that has recently been reported within the Sudanese community across Australia. Data-based searches through PsychInfo, Science Direct, and Web of Science, using terms such as 'Sudan, Australia, refugees, difficulties, acculturation and acculturation stress' were conducted. Overall, research with Sudanese refugees is limited. According to the authors' knowledge there are no studies conducted specifically on the acculturative stress of the Sudanese refugees. Therefore, general refugee literature was examined to understand the Sudanese refugees' acculturation stress. The following sections review the literature to address the above two goals. Finally, gaps in investigations are pointed out and directions for future research are discussed.

\section{Background of Sudan: Demographics, Culture, Conflict, and Exodus}

Sudan is one of the world's poorest countries, with extremely low health, social and economic indicators (Mayotte, 1994). Sudan's population was estimated to be 40 million in 2009 (Sudan Watch, 2009). It is a young population, with $45 \%$ of the population aged under 15 and an estimated life expectancy of 57 years. The country can be divided into a north and a south region. North of Sudan is drier and financially stronger that other parts of the country. Most of the people living in this region are Muslims and associate with the Saharan culture. Seventy-nine per cent of the entire population live in the north. The southern part of the country is tropical and underdeveloped and 8.26 million or $21 \%$ of the entire population live in the south and are predominantly Christians or follow indigenous beliefs. Darfur, the western region, is also very underdeveloped.
The south and the western regions are inhabited by the two large tribes of the region: the Dinkas and the Nuer (UNDP, 2008). Ethnically, Sudan is one of the most diverse countries in the world, with 400 languages and dialects, 19 main ethnic groups and 500 ethnic subgroups, several of which — such as Dinka, Neur, and Nuba - are represented in Australia (Poppitt \& Frey, 2007; UNDP, 2008). Sudanese culture is extremely heterogeneous and cultural practices, dress styles and food preparation vary across the country. However, similarities also exist in many aspects of their way of life. Sudanese society is collectivistic and hierarchical in nature (Hillier, 2002). Traditionally, Sudanese men, who are able to afford the cost, have more than one wife. Marriages tend to be arranged and a dowry is usually paid to the bride's family (e.g., the Dinka tribe pays dowry in cows; Dei Wal, 2004). The family forms the basis of the Sudanese social structure. Families tend to be large, to embrace extended family and to be very patriarchal. The men are authoritarians, heads of the household and lead lives quite separate from women in a number of activities, both within the home and socially (Hillier, 2002; Tempany, 2009). Sudanese women expect to be disciplined by their husbands and the women are expected to maintain the home and care for the children.

The history of conflict in Sudan is ongoing, with the first civil war beginning in 1955, just prior to it acquiring independence from Britain. This war, known as the Anyanya rebellion, lasted until 1972. During this time over 500,000 people were killed. However, the tensions were not completely dispelled, and war broke out again in 1983 and continued until 2005, when the Naivasha peace agreement was signed (Global Security Organisation, 2008). In spite of the peace negotiations, the situation in western Darfur is still very serious due to the intense combat ('Sudan Population', 2005). Although incredibly complex, the conflict can be described in more simplistic terms as conflict between rebel armies in southern Sudan representing diverse African ethnic groups of indigenous and Christian beliefs, in a struggle to overthrow the northern dictatorship representing mainly Arab Muslim interests. The basic goal was a bid for political autonomy or independence for southern Sudan (Mayotte, 1994). Victory for the South would mean a repeal of Muslim Shari'a laws, the removal of Arabic as the official language and the promotion of economic development in the South (Mayotte, 1994).

In addition to the war between the north and south, there has also been constant intertribal warfare between the Dinka and the Nuer, the two largest tribes in the south, with this conflict largely centred in the western Darfur region (Global Security Organisation, 2008; Taha $\&$ De Mabior, 2005). The fighting in the region intensified in 2003 when two armed groups emerged in opposition to the government, the Sudan Liberation Army (SLA) and the Justice Equality Movement (JEM). 
The government of Sudan has reportedly sponsored a militia group, predominantly of Arab background from the Darfur region, known as the Janjaweed, who supported the regular armed forces in attacks on the civilian population (Global Security Organisation, 2008; Taha \& De Mabior, 2005). The Sudanese government also launched indiscriminate attacks from the air on population centres, usually at night or in the early morning. The Janjaweed, on the other hand, tended to focus on the villages, burning property and crops, stealing livestock, raping women and killing civilians (Global Security Organisation, 2008; Taha \& De Mabior, 2005). This intense fighting, combined with widespread starvation among southern Sudanese as a result of the scorched earth tactics of the rebels and the withholding of food and medical aid by government troops, led to the internal displacement of 5 million people in this region, and a death toll as high as 2 million, with the death of 100 people per day (Mayotte, 1994). Darfur, because of the severe nature of the conflict and genocide, is considered as the worse humanitarian disaster on earth (Sudan Watch, 2009). A large study $(N=1274)$ of internally displaced individuals camped in south Darfur's Nyala district identified severe neglect of the psychosocial, physical and mental health needs (Kim, Torbay \& Lawry, 2007).

This exodus of people from their country has made Sudan the second largest originator of refugees in the modern world (UNHCR, 2008). Over 600,000 southern Sudanese fled to neighbouring countries, including Kenya and Egypt. In Kenya's northern frontier district, Kakuma camp was established in 1991 to house asylum seekers. This camp is larger than most of the Kenya's towns. It is home to over 80,000 refugees, of whom 60,000 are Sudanese (Hillier, 2002). At Kakuma, living conditions are very harsh, with no proper and safe accommodation. In this camp, drinking water is unhygienic, there are food shortages, malnutrition and illnesses are high and very limited health and education services are available. Water and food is strictly rationed (Sudan Watch, 2006). Each camp resident received one litre of water per day to drink, cook and wash. Similarly, each person receives 3.5 kilograms of maize per week. Egypt has 30,000 Sudanese refugees registered with UNHCR, with a further 7,000 to 8,000 Sudanese arriving in Egypt each year (Hassan, 2000). Southern Sudanese, who are Egypt's largest refugee population, are considered outsiders. They are unable to work legally in Egypt, find housing or have access to national health facilities or government schools (Cocker, 2004). Most of them are persecuted and harassed by the locals (Khawaja et al., 2008).

A recent study conducted by Meffert and Marmar (2009) studied the Darfur refugees staying at a camp based in Cairo. The authors identified depression, trauma and domestic and community violence. They emphasised the need to address the mental health issues of the camp residents. Egypt and Kenya are used as transit points to apply for a humanitarian entry into a safer country. It is important to note that the application process takes from months to years ('Refugees' Experience of Legal Protection in Kakuma Camp', 2009). Further, a very small number of those in camps are successful in entering a developed western country on humanitarian grounds. Although, there is no definite figure available for those who been granted entry in the West, it is estimated that thousands were accepted on humanitarian grounds by the United States, United Kingdom, Scandinavian countries, New Zealand and Australia (Kotch, 2007). The majority of the population is still suffering from an ongoing crisis. Not surprisingly, these traumatic experiences and the social, physical and mental challenges of adapting to forced migration, cause very serious psychological stress among refugees from Sudan.

\section{Trauma, Adjustment and Psychological Wellness}

Many refugees have survived the worst forms of human brutality and human rights violations (Tempany, 2009). Most Sudanese refugees have been exposed to traumatic events such as torture, threats to their own lives and those of their families, rape and sexual abuse, food shortages and destruction of homes and villages (Schweitzer et al., 2006). Studying the effects of this trauma on refugees has proven difficult due to the hesitancy of refugees to participate in studies, and the fact that services assisting in resettlement do not regard research as a priority. However, recent studies yield consistent results confirming that trauma, particularly torture and rape, increase the risk of adverse outcomes for individuals and for family relationships (Lie, 2002). These negative experiences also increase the vulnerability of individuals to future stressful events (Melville, 2003).

A study involving 1413 Vietnamese refugees in Australia (mean length of time in the country was 11.2 years and length of time since exposure to traumatic events was 14.8 years) revealed that trauma exposure was not only the most important predictor of current mental health status but also that people who had been exposed to more than three traumatic events had a heightened risk of persistent mental illness (Steel et al., 2002). In a recent Australian study Schweitzer and colleagues (Schweitzer et al., 2006) found that Sudanese refugees settled in Australia had experienced at least one of the sixteen categories of traumatic events distinguished by the Harvard Trauma Questionnaire. Traumatic events most frequently cited were murder of a family member or friend, lack of food, water and shelter and separation from family.

Melville (2003) explored the impact of premigration trauma involving separation from family among a group 
of 43 resettled adult Sudanese refugees in Australia. It showed that separation from family caused significantly greater emotional stress than exposure to other past trauma. Refugees in exile have experienced stress mainly as a result of separation from their families (Miller, Worthington, Muzurovic, Tipping, \& Goldman, 2002). Further, in a study exploring the impact of pre and postmigration trauma on Sudanese refugees in Australia, Schweitzer et al. (2006) also found that separation from family was significantly associated with current mental health, and that individuals whose families were no longer intact experienced greater emotional stress. The same authors reported that separation from family resulted in less meaningful representations of purpose in life, because the family provides a source of emotional support and reinforces a sense of self and cultural identity. The psychological stress generated by weak or absent family attachments is also associated with increased vulnerability and with poor adjustment for Sudanese refugees settling in Australia (Schweitzer et al., 2006). The cultural concept of self arises from knowledge of, and interaction with, family members (Sonderegger, Barrett, \& Creed, 2004); therefore, participation and membership in family groups, or other social structures, significantly benefit personal wellbeing and reduce the negative effects of stressful life events (McMichael \& Manderson, 2004).

Other changes in structure and roles within Sudanese families following resettlement can also greatly affect the family institution (Dei Wal, 2004). Previous studies have shown that trauma and separation from family are significant predictors of mental health problems; however, it is clear that postmigration difficulties, including the level of support during resettlement, are also important for psychological wellbeing (McMichael \& Manderson, 2004; Miller et al., 2002; Schweitzer et al., 2006; Sonderegger et al., 2004). Migration involves not only movement between places but also movement between social relationships and community settings. Moving to a new country and learning the social norms of a new culture is a process that generates psychological distress (Miller et al., 2002; Schweitzer et al., 2006; Sonderegger \& Barrett, 2004). Positive mental health is derived directly from positive relationships whereas, conversely, poor social networks are associated with poor physical and mental health (McMichael \& Manderson, 2004). Feeling accepted in a particular environment requires both external support and internal feelings of self-esteem and belonging, which are linked with the ability to cope with stressful situations. Deficient social support has been found to cause increased levels of anxiety and poor mental health in migrants to Australia (Sonderegger et al., 2004).

The social support received from extended family and other social groupings within the Sudanese community is a significant determinant of mental health functioning, the loss of which may involve ongoing trauma for immigrants (Sonderegger et al., 2004). Moreover, problems with employment often increase difficulties postmigration (Lie, 2002; Miller et al., 2002; Schweitzer et al., 2006). Dissimilar social and cultural backgrounds of refugees and the members of their host country can create psychological and emotional stress, including a sense of isolation. Additionally, their attempt to adjust to new ideas and norms, may lead to confusion, frustration and disempowerment (DIMA, 2006). Furthermore, the factors that deter the newly arrived from integrating effectively with the host society are literacy and language difficulties, problems within the education and career sector and the violence within the community.

\section{Language, Education, Vocation and Violence Within the Community}

Language has emerged as a key factor for environmental mastery (Khawaja et al., 2008). It provides a means of integration through communication and enhances the understanding between two cultures (Poppitt \& Frey, 2007). Perceived second-language proficiency leads to greater self-esteem and less stress (Noels, Pon, \& Clement, 1996) whereas second-language difficulties are significantly associated with subcultural identity (Taylor \& Doherty, 2005), or being different from the mainstream culture. Seventy seven per cent of refugees settling in Queensland, Australia reported poor or nil English proficiency (DIMA, 2006). Developing English language skills is an important precursor for social inclusivity and participation in Australian life. It is a route to securing employment, successful interaction with the community and for better access to health and housing services. However, Sudanese, particularly female and older members of the community, often arrive in Australia unable to speak English and with little or no literacy skills, which subsequently creates challenges in accessing education and training that would enhance employment prospects (DIMA, 2006).

Language difficulties are the most common cause of vocational and educational postsettlement difficulties in Australia (Thlabano \& Schweitzer, 2007). However, the Sydney Morning Herald has highlighted the fact that communities are suffering from state governments' cuts to funding for community colleges running programs assisting refugees with learning English (Alexander, 2008). Despite receiving compulsory English tuition provided by the government the Sudanese refugees in Australia have not been able to develop English language proficiency. This tuition is insufficient as they are still unable to communicate effectively or complete official documentation, including forms required for doctors or schools. Further, they experience adverse health effects. Members of the Sudanese community state they are unable to read food labels in supermarkets, and are 
either going hungry or not eating properly (Alexander). Thus, limited secondary language proficiency is impacting on postmigration settlement in many ways.

Despite, or perhaps because of, having limited access to schooling, Sudanese value education and professional achievement highly (Perry, 2008). However, there are several difficulties experienced by the newly arrived that impact on their learning in Australian schools and other training institutions. Tong, Huang, and McIntyre (2006) have indicated the challenges immigrant youth encounter as a result of negotiating two cultures and languages. Difficulties in language and communication can cause withdrawn or aggressive behaviour, and students report feelings of anxiety about not being able to read and write (The Victorian Foundation for Survivors of Torture, 2005). It is important to note that Sudanese refugees have come predominantly from aversive camps, which lacked social structure and prevented adequate psychosocial and cognitive development (Fraine \& McDade, 2009). Therefore, they have difficulties learning and adapting to the classroom environment and routines (Hillier, 2002; Jackson, 2007). Further, their previous difficulties and language barriers thwart general interaction, social inclusivity and involvement in community activities (McMichael \& Manderson, 2004).

The refugees generally do not feel skilled and confident enough to join the host society's events and activities (Porter \& Haslam, 2005). The intricacy increases when the host group, with already established ties, may not be keen to interact with the newly arrived (Dominguez \& Maya-Jariego, 2008). This social isolation combined with limited social ties due to being new in a country often leads to a sense of loneliness and significant distress (McMichael \& Manderson, 2004). Limited education and language skills prevent refugees from securing employment and therefore cause financial constraints (Blair, 2000). Social and financial difficulties have been shown to contribute to anxiety and depression (McMichael \& Manderson). Lack of interaction between the newly arrived and the host society has caused misunderstandings, and many Sudanese in Australia claim that they are misunderstood and feel under siege in their new country (Roberts, 2007). The media had frequently run reports of violence among the Sudanese, particularly the young men ('Politically Correct Rubbish From The Australian', 2007). Some members of the Sudanese community, when interviewed, reported that the younger men may not fit in and do not appreciate the opportunity they have been given (Lehmann, 2007). Moreover, tribal divisions endemic in Sudan persist in Australia, resulting in clashes between Dinka and Nuer clans, and between the Sudanese youth and the authorities (Roberts, 2007). Aggression has also been reported at the family level.

Evolving family power dynamics during relocation often result in an increased incidence of domestic vio- lence (Yakushko et al., 2008). Domestic violence has become a problem within the Sudanese community with alarming incidents reported of husbands battering wives and children (Australian Police Multicultural Advisory Bureau, 2007). In southern Sudan women expect to be disciplined by their husbands and are not allowed to talk about it, as it is considered a family problem (Keller \& Brennan, 2007). In Sudan if they choose to leave their husbands they also have to leave the children; subsequently, many women choose to endure the violence for their sake of the children. In Australia, there is support available for abused women, but the Sudanese women may not access it, either due to a reluctance to discuss it with strangers, or because they are unaware of the services available to them. Alternatively, agencies who can provide support may not have tailored their services to meet the needs of this community (Dei Wal, 2004).

Overall, language proficiency, education, employment and social interaction are all important for the process of acculturation, which involves changes in the original beliefs and cultural values in order to adapt to the new settings. The adaptation complexities encountered by the Sudanese in Australia, in particular the aggression reported at the family and community level, seems to suggest acculturation difficulties.

\section{Acculturation}

Culture is a learned behaviour that is shared and transmitted from one generation to the next for the purposes of human adjustment and adaptation. It encompasses institutions, roles, values and beliefs and learned behaviours (Ahern, 1997, as cited in Tempany, 2009). It is a part of each individual and helps in making meaning out of life. In Australian culture, the person is seen as a self-contained unit, independent of others. This view is not shared by the Sudanese who, as a collectivist society, view the individual as part of a family or community. Therefore, it is important to examine the cultural context of any behaviour, including trauma and stress. Sudanese refugees, who grew up in one cultural context have had to re-establish their lives in another and have to adapt to new concepts as a result of their migration. Thus, the complex pattern of continuity and change that occurs is the process of acculturation (Berry, 1997). Redfield, Linton, and Herskovits (1936, p. 149) provided a classical definition of acculturation: 'Acculturation comprehends those phenomena which result when groups of individuals having different cultures come into continuous first-hand contact with subsequent changes in the original culture patterns of either or both groups' (as cited in Berry, 1997, p. 7).

More simply, acculturation has been described 'as the meeting of cultures and the resulting changes' (Berry, 2005 , p. 698), although in practice it induces more changes in one group than the other (Berry, 1997). Changes in behaviour, attitude and values occur for all 
groups of people coming into contact with persons and groups from other cultures (Williams \& Berry, 1991). Subsequently, acculturation phenomena occur in relation to the interaction of the two groups, rather than being isolated to the acculturating group. Acculturation and its outcome, adaptation, is multifaceted; therefore, Williams and Berry (1991) suggest that there are several points to consider when studying acculturation, including understanding and accepting the culture of the acculturating group. Moreover, Berry (2001) proposes a two-level model to address acculturation. According to this model, acculturation consists of changes that occur on a group level and changes that occur on an individual psychological level.

This distinction highlights the importance of looking at the interaction between levels, as well as recognising that, although change may be extensive within a group, individual changes vary greatly (Berry, 1997). Further, there is often a strong influence of family dynamics on acculturation (Morrison \& James, 2009). Acculturation is a process that does not necessarily occur uniformly within family groups. As a result tension is observed among different generations. Similarly, acculturation can also vary between married or intimate couples. Acculturation constitutes a double transition for married Sudanese refugees, as both individuals within the marriage are adapting (Attaca \& Berry, 2002).

\section{Acculturation Stress: Intergenerational Conflict, Gender Differences, Marital Relationships}

One common consequence of acculturation is the breakdown of social and cultural norms, and distress at an individual level. Conflict between shedding aspects of the culture of origin and learning new aspects of the host culture is referred to as acculturative stress (Berry, 1997; Poppitt \& Frey, 2007). The effects of acculturation are complex and the stress of adjusting to a new cultural environment impacts on psychological, social and physical levels. This stress is exacerbated by loss of social support and changes in family dynamics (Hwang \& Ting, 2008). Acculturation stress is also moderated by factors such as the immigration status of an individual: whether the individual is a voluntary immigrant or refugee (Williams \& Berry, 1991). In the case of refugees, immigration is not chosen. In such cases the impact of acculturation stress is likely to be greater (Poppitt \& Frey, 2007; Schweitzer et al., 2006). The level of marginalisation, or separateness, can escalate or ameliorate stress, as can socioeconomic status (Williams \& Berry, 1991). Duration of stay in the host country, language ability, as well as the country of origin are associated with distress (Hadley \& Patil, 2009). These researchers reported the stress to be higher for those who had migrated from an African country. Further, age is a factor in acculturative stress. Adolescents in particular are more susceptible to experiencing acculturation problems (Poppitt \& Frey, 2007; Williams \& Berry, 1991). Additionally, parents have found it difficult to deal with children who belong to two cultures (Kaplan, 2009). Some recent studies and media reports have highlighted the possibility that refugees from Sudanese community who have settled in Australia might be experiencing acculturative stress (Dei Wal, 2004; Khawaja et al., 2008; Roberts, 2007; Poppitt \& Frey, 2007; Schweitzer et al., 2006). However, this stress has not been studied thoroughly. Due to the scarcity of such studies, general literature on refugees was examined to understand the inferred acculturative distresses of these new arrivals.

\section{Intergenerational Conflict}

The influence of acculturation stress within families can be viewed in the context of adaptation changes that occur within the group. Various generations within the family may be at different levels of acculturation, which is often associated with emotional distress and conflicts. Intergenerational conflict within refugee communities results in increased interpersonal distance between family members. Pouch (2006), a Sudanese refugee who presented a paper at an intergenerational programs conference in Melbourne, stated that three generation groups exist, creating challenges that confront every Sudanese migrant family. She argued that these generations consist of the older people of the community, the younger generation aged between 12 and 25, and finally the children born during exile or in Australia. According to Pouch (2006) it is the role of the older members to sustain Sudanese norms, values, language and culture. The elder's role is very important, as the younger generations who have fled war-torn Sudan have little memory of traditional practices and tend to adopt a culture of violence legitimised by their exposure to the power of guns (Pouch, 2006). Pouch (2006) expressed concern that there was a risk of elders failing to transmit their traditions to Sudanese youth who arrive in Australia with high expectations that require more or less immediate gratification. Young people struggle to incorporate the values of Sudanese culture with those of the host country, thereby creating complex internal conflicts.

Children attend school immediately after arriving in Australia and, because acculturation tends to occur more rapidly in public rather than private settings, they usually adapt to their new culture more quickly than their elders, which can result in conflict between the generations (Poppitt \& Frey, 2007; Pouch, 2006) especially when they begin to discard aspects of their culture (Rice, Rice, \& Dhamarak, 1993). A study conducted in the US exploring the relationship between level of acculturation and intergenerational conflict among 80 Laotian American adolescents and their parents showed that the degree of intergenerational conflict increased as the differences between the parents and the adolescents 
in their reported and perceived cultural practices and values also increased (Bounkeua, 2008). Further, results from a study of South Asian students focusing on acculturation dissonance and intergenerational conflict with their immigrant parents support this conclusion (Hamid, 2008). These South Asian students had greater levels of American acculturation, unlike their parents, who were low on American acculturation. In this study, family conflict was reduced in cases where the parent's orientation to American culture was greater (Hamid, 2008). Nevertheless, elderly people's perception of the cultural gap between themselves and their adult children has appeared to be associated with their depression (Mui \& Kang, 2006). Similarly, intergenerational conflicts and parenting styles are linked with youth distress (Lim et al, 2009). These difficulties, which seem to be affecting all generations, have emerged as serious for the seniors as well as for the youth and can hinder their postmigration adjustment. This conflict is not experienced similarly for males and females and gender differences in intergenerational conflict were found in a group of Vietnamese American youth, with intergenerational conflict more detrimental to psychological wellbeing for males than females (Vu, 2008).

\section{Gender Differences}

Gender differences occur in the level of acculturation stress experienced by couples (Darvishpour, 2002; Morrison \& James, 2009; Renner \& Salem, 2009). Traditional roles undergo change where the host society is very different from the original culture. There is an evidence of stress when wives, in addition to their traditional roles as a homemaker and a mother, had to take up employment (Hyman, Guruge, \& Mason, 2008). Such changes may cause difficulties and discourage women from entering paid work. Conversely, the dominant, authoritarian role of men is challenged following a move to a more egalitarian culture (Darvishpour, 2002; In-Soo, 1997). Resettlement in a western country may provide women from a patriarchal society with an increased sense of power and independence, particularly if they have had to enter the workforce and may be earning more income than their male partners. Men, however, can experience the opposite effect, with resettlement leading to unemployment, a loss of power and a reduced sense of identity (Nilsson et al., 2008). Renner and Salem (2009) identified distinct gender differences among a group of 150 asylum seekers from Chechnya, Afghanistan and West Africa in reported symptoms and coping strategies. Men reported detachment, while women reported more somatic symptoms, emotional outbursts and loss of sexual interest. Marked differences were also found in coping strategies, with the women tending to care for their children and participate in activities within the home, while the men chose to look for outside work and to socialise (Renner \& Salem, 2009).
A study of Iranian refugees resettled in Sweden found that they had significantly different experiences and attitudes towards their new country. According to men, the Swedish lifestyle caused conflict in the family because the women gained more freedom socially. Both women and children in the family rejected attempts by the men to control the family (Darvishpour, 2002). Men reported feeling misunderstood by authorities who, they said, supported the women. However, the Iranian women's reported experience of immigration was much more positive because their situation and opportunities in Sweden significantly improved following resettlement (Darvishpour, 2002).

\section{Marital Relationships}

The influence of acculturation stress on marital relationships can be viewed within the context of individual adaptation to cultural change (Flores, Tschann, Van Oss, $\&$ Pantoja, 2004). The influence of family dynamics and the strategies each partner utilises can lead to conflict (Morrison \& James, 2009). Conflict may occur when a low acculturated partner expects the other partner, who has already adapted to the dominant host culture, to continue to follow premigration values and traditions (Castillo, Conoley, Brossart, \& Quiros, 2007). A husband or wife who is less acculturated may perceive the behaviour of the more highly acculturated partner as a threat, thereby increasing their own level of acculturative stress, which in turn leads to conflict (Lee \& Liu, 2001).

Results from a study examining the relations between acculturation, domestic violence and mental health among 62 refugee women from Somalia in the United States revealed greater reported domestic violence towards women who spoke English well and were more assimilated (Nilsson, Brown, Russell, \& KhamphakdyBrown, 2008). Similarly, Lovell, Tran, and Nguyen (1987) reported that female refugees from South-East Asia, whose culture like the Sudanese involves a patriarchal extended family model, as a result of the change in roles following resettlement in America reported an increase in domestic violence and marital separation. In a study examining the changing power relationship within marriage following immigration among Iranian refugees in Sweden, the women reported increased conflict with their husbands, particularly around their increased economic independence. Women were often able to secure further education and thereby increased their employment prospects. Similarly, conflict as a result of a struggle for domestic power was reported in a study with Mexican couples who had immigrated to the US, with the women attempting to change and equalise the power balance in the relationship (Flores et al., 2004).

Sweden is not a patriarchal society, and dependency between spouses is more mutual. Accordingly, a study of Iranian refugees in Sweden showed that Iranian men were no longer viewed by their wives as being dominant. 
Specifically, as the difference in power resources between the spouses decreased, the relationship deteriorated. Consequently, women were more easily able to secure a divorce and live independently in their new country (Darvishpour, 2002).

The studies discussed reveal a pattern of increased domestic violence and separation following resettlement due to differences in rate of acculturation and a shift of power in the relationship. Such relationship distress is a sign of acculturative stress. However, the aforementioned studies have not identified how this stress manifests or the underlying cause of the domestic violence, what cultural norms and values are threatened when power shifts, and how this relationship distress is experienced by each member of the couple.

In Sweden, rates of divorce were higher among immigrants than among native Swedes and were highest among African couples (Darvishpour, 2002) and, in 1999 in Australia, 42\% of divorces were granted to couples where either one or both parties were born in an overseas country (Family Court of Australia, 2004). Although there are no statistics isolating any one particular cultural group and these statistics may not be entirely related to acculturations stress, it is of some concern that nearly half of Australian divorces are between couples where one or both may be experiencing acculturation stress.

\section{Conclusion}

The review aimed to inform Australian mental health professionals about the plight and the possible acculturative stress of Sudanese refugees settled in Australia. The studies examined outlined the conflict in Sudan, which has created the displacement of so many of its citizens. Elements of Sudanese culture and Sudanese experience as refugees in transit have also been discussed briefly. The research was reviewed in order to highlight the psychological effects of trauma and adjustment and to show how resettlement in Australia has affected the refugees. This discussion was followed by the theory of acculturation and of difficulties arising from acculturation in refugee communities, one consequence of which is acculturation stress. Finally, the possible effects of acculturation on families, gender differences and marital relationships were considered.

The literature review revealed that, following resettlement, difficulties are experienced at an individual, couple, family and community level. There are changes in family dynamics following the survival of traumatic experiences, or when there has been a forced move to another society - particularly if it is to one that differs markedly in core values (Darvishpour, 2002; In-Soo, 1997; Nilsson et al., 2008). Further, the literature indicates that differences in levels of acculturation between family members causes conflict, which in patriarchal refugee communities is typically more pronounced among males, whose dominant role is bought into question.

Acculturation-related difficulties that have been observed in other refugee groups are likely to exist within the Sudanese community of Australia who have endured traumatic experiences, have been forced to leave their homes and have moved from a collectivist to an individualist society, eroding their values, norms and customs. Other studies show that the consequential stress threatens the family unit because of intergenerational conflict (Poppitt \& Frey, 2007; Pouch, 2006). These findings, together with alarming stories of domestic violence within the Sudanese community (Australian Police Multicultural Advisory Bureau, 2007; Lehmann, 2007), statistics regarding divorce rates of refugees from Africa in Sweden (Darvishpour, 2002) and divorce rates in Australia (Family Court of Australia, 2004) raise concerns for Sudanese refugee families. The potential for family breakdown among people who have already lost so much is likely to increase acculturation stress significantly (Miller et al., 2002; Melville, 2003; Schweitzer et al., 2006). It also threatens to place a greater strain on government, NGOs and other services that may be required to provide financial or practical support to a fragmented community.

Finally, no studies were identified that specifically conducted an in-depth analysis of the Sudanese refugees' acculturation stress at various age levels and at the individual, couple, family and community levels. Keeping in mind the elements of aggression within this community, it is important to study the young men who appear to be struggling with the acculturation process. Further, research exploring the manifestation and impact of acculturation stress on the Sudanese refugees' interpersonal relations in the form of intergenerational, familial and marital conflicts is warranted. The by-product of any such research has the possibility of assisting the Australian Sudanese community, governmental, and other agencies by providing information that may serve to prevent or at least ameliorate acculturation stress.

\section{References}

Alexander, H. (2008, May 9). Communities suffer as college cuts bite. The Sydney Morning Herald, pp. 6.

Attaca, B., \& Berry, J. W. (2002). Psychological, sociocultural and marital adaptation of Turkish immigrant couples in Canada. International Journal of Psychology, 37, 13-26.

Australian Police Multicultural Advisory Bureau. (2007). Achievements. Retrieved from http://en.wikipedia.org/wiki/ Australasian_Police_Multicultural_Advisory_Bureau

Berry, J.W. (1997). Acculturation: Living successfully in two cultures. International Journal of Intercultural Relations, 29, 697-712.

Berry, J.W. (2001). A psychology of immigration. Journal of Social Issues, 3, 615-633. 
Berry, J.W. (2005). Immigration, acculturation and adaptation. Applied Psychology: An International Review, 46, 5-34.

Blair, R.G. (2000). Risk Factors associated with PTSD and major depression among Cambodian refugees in Utah. Health \& Social Work, 25(1), 23-30.

Bounkeua, P.K. (2008). The relationship between differential acculturation strategies, perception of intergenerational conflict, and depression in Laotian-American adolescents. (Doctoral dissertation) Seattle Pacific University. Retrieved December 7, 2009, from http://proquest.umi.com/ pqdlink? Ver $=1 \&$ Exp $=12-06-2014 \& \mathrm{FMT}=7 \& \mathrm{DID}$ $=1404353811 \&$ RQT $=309 \&$ attempt $=1$

Castillo, L.G., Conoley, C.W., Brossart, D.F., \& Quiros, A. (2007). Construction and validation of the intragroup marginalization inventory. Cultural Diversity \& Ethnic Minority Psychology, 13, 232-240.

Cocker, E.M. (2004). Traveling pains: Embodied metaphors of suffering among Southern Sudanese refugees in Cairo. Culture, Medicine and Psychiatry, 28, 15-39.

Coffrey, M. (2004). Life in transit; the experience of Sudanese refugees arriving in Australia. Sudanese Online Research Association. Retrieved from http://sora.akm.net.au/publish. php? subaction $=$ showfull\&id $=1100194204 \&$ archive $=\&$ start from $=$ \&ucat $=38$ \&

Darvishpour, M. (2002). Immigrant women challenge the role of men: How the changing power relationship within Iranian families in Sweden intensifies family conflicts after immigration. Journal of Comparative Studies, 33, 271-296.

Dei Wal, N. (2004). Southern Sudanese culture: Education and refugee students from Southern Sudan. Retrieved 9 September 2008 from The Victorian Foundation for Survivors of Torture web site: http://www.foundationhouse.org.au/home/index.htm.

Department of Immigration and Multicultural Affairs. (2006). Humanitarian programme statistics. Retrieved 12 September 2006, from http://www.immi.gov.au/media/ statistics/statistical-info/visa-grants/refugee.htm

Dominguez, S., \& Maya-Jariego, I. (2008). Acculturation of host individuals: Immigrants and personal networks. American Journal of Community Psychology, 42, 309-327.

Family Court of Australia. (2004). Cultural Diversity Audit Report. Retrieved April 10, 2009, from http://www.familycourt.gov.au/wps/wcm/resources/file/ebeb7708fca8892/ Diverstiy_Audit_Report.pdf

Flores, E., Tschann, J.M., Van Oss M.B., \& Pantoja, P. (2004) Marital conflict and acculturation among Mexican American husbands and wives. Cultural Diversity and Ethnic Minority Psychology, 10, 39-52.

Fraine, N., \& McDade, R. (2009). Reducing bias in psychometric assessment of culturally and linguistically diverse students from refugee backgrounds in Australian schools: A process approach. Australian Psychologist, 44, 16-26.

Global Security Organisation. (2008). Military menu: Sudan civil war. Retrieved September 1, 2008, from http://www. globalsecurity.org/military/world/war/sudan.htm

Hadley, C., \& Patil, C. (2009). Perceived discrimination among three groups of refugees resettled in the USA: Associations with language, time in the USA, and the continent of origin. Journal of Immigrant and Minority Health, 11, 505-512.
Hamid, R.M. (2008). Perceived parental acculturation and psychological well-being of South Asian college students and young adults. Available from ProQuest Dissertation Theses. DAI-B 68/08, p. 5573, Feb 2008. Retrieved from: http:// gradworks.umi.com/32/80/3280168.html

Hassan, A. (2000). Sudanese refugees: Down and out in Cairo. Retrieved 7 December 2009 from http://www.worldpress. org/Mideast/312.cfm

Hillier, A. (2002). The Southern Sudanese in Western Australia: Worlds apart. Presentation at AMEP National Conference, Canberra.

Hyman, I., Guruge, S., \& Mason, R. (2008). The impact of migration on marital relationships: A study of Ethiopian immigrants in Toronto. Journal of Comparative Family Studies, 39, 149-170.

Hwang, W.C., \& Ting, Y.Y. (2008). Disaggregating the effects of acculturation and acculturation stress on the mental health of Asian Americans. Cultural Diversity and Ethnic Minority Psychology, 14, 147-154.

In-Soo, L. (1997). Korean immigrant women's challenge to gender inequality at home: The interplay of economic recourses, gender and family. Gender and Society, 11, 31-51.

Jackson, A. (2007, October 23). Sudanese dropped in a strange land. The Melbourne Age, p. 4.

Kaplan, I. (2009). Effects of the trauma and the refugee experience on psychological assessment processes and interpretation. Australian Psychologist, 44, 6-15.

Keller, E.M., \& Brennan, P.K. (2007). Cultural consideration and challenges to service delivery for Sudanese victims of domestic violence: Insights from service providers and actors in the criminal justice system. International Review of Victimology, 14, 115-141.

Khawaja, N.G., White, K., Schweitzer, R., \& Greenslade, J (2008). Difficulties and coping strategies of Sudanese refugees: A qualitative approach. Transcultural Psychiatry, $45,489-521$.

Kotch, D.M. (2007). Sudanese community in Australia in the media spotlight. CBM News. Retrieved December 15, 2009, from: http://www.gbmnews.com/articles/1618/1/Sudanesecommunity-in-Australia-in-the-media-spotlight/Page1.html

Kim, G., Torbay, R., \& Lawry, L. (2007). Basic health, women's health, and mental health among internally displaced persons in Nyala Province, South Darfur, Sudan. American Journal of Public Health, 97, 353-361

Lee, R.M., \& Liu, H.T. (2001). Coping with intergenerational family conflict: Comparison of Asian American, Hispanic, and European American college students. Journal of Counseling Psychology, 48, 410-419.

Lehmann, M (2007). Ethnic crime: Somalians and Sudanese. Australian News Commentary. Retrieved December 7, 2009, from http://australian-news.net/Ethnic_crime_ African.htm

Lie, B. (2002). A 3-year follow-up study of psychosocial functioning and general symptoms in settled refugees. Acta Psychiatrica Scandinavica, 106, 415-425.

Lim, S.L., Yeh, M., Liang, J., Lau, A.S., \& McCabe, K. (2009). Acculturation gap, intergenerational conflict, parenting 
style, and youth distress in immigrant Chinese American families. Marriage \& Family Review, 45, 84-106.

Lovell, M.L., Tran, T., \& Nguyen, C. . (1987). Refugee women: Lives in transition. International Social Work, 30, 317-325.

Mayotte, J. (1994). Civil war in Sudan: The paradox of human rights and national sovereignty. Journal of International Affairs, 47, 497-524.

McMichael, C., \& Manderson, L. (2004). Somali women and well-being: Social networks and social capital among immigrant women in Australia. Human Organisation, 63, 88-99.

Meffert, S.M., \& Marmar, C.R. (2009). Darfur refugees in Cairo: Mental health and interpersonal conflict in the aftermath of genocide. Journal of Interpersonal Violence, 24, $1835-1848$.

Melville, F. (2003). The relationship between trauma, separation from family and emotional well being in resettled Sudanese refugees. (Unpublished honours thesis) Queensland University of Technology, Brisbane, Australia.

Miller, K.E., Worthington, G.J., Muzurovic, J., Tipping, S., \& Goldman, A. (2002). Bosnian refugees and stressors of exile: A narrative study. American Journal of Orthopsychiatry, 72, 341-354.

Morrison, M., \& James, S. (2009). Portuguese immigrant families: The impact of acculturation. Family Processes, 48, 151-166.

Mui, A.C., \& Kang, S-Y. (2006). Acculturation stress and depression among Asian immigrant elders. Social Work, 51, 243-256.

Nilsson, J.E., Brown, C., Russell, E.B., \& Khamphakdy-Brown, S. (2008). Acculturation partner violence, and psychological distress in refugee women from Somalia. Journal of Interpersonal Violence, 23, 1654-1663.

Noels, K., Pon, G., \& Clement, R. (1996). Language, identity and adjustment: The role of linguistic self-confidence in the acculturation process. Journal of Language and Social Psychology, 15, 246-264.

Perry, K.H. (2008). From storytelling to writing: Transforming literacy practices among Sudanese refugees. Journal of Literacy Research, 40, 317-358.

Politically correct rubbish from the Australian (2007, January 26). The Australian. Retrieved December 7, 2009, from http://australian-news.net/Ethnic_crime_African.htm

Poppitt, G., \& Frey, R. (2007). Sudanese adolescent refugees: Acculturation and acculturation stress. Australian Journal of Guidance and Counselling, 17, 160-181.

Pouch, G. (2006). Intergenerational conflict, changes and resolutions within the Sudanese community: Parents vs young people. Published in Proceeding of the International Consortium for Intergenerational Programmes, Melbourne, Australia.

Porter, M., \& Haslam, N. (2005). Pre-displacement and postdisplacement factors associated with the mental health of refugees and internally displaced persons: A meta-analysis. JAMA, 294, 602-612.

Refugees' experience of legal protection in Kakuma camp. (2009). Kakuma News Reflector-A Refugee Free Press 1(4-5). Retrieved December 15, 2009, from http://kakuma. wordpress.com/2009/05/12/refugee-experiences-of-legalprotection-in-kakuma-camp/ I

Renner, W., \& Salem, I. (2009). Post-traumatic stress in asylum seekers and refugees from Chechnya, Afghanistan, and West Africa: Gender differences in symptomatology and coping. International Journal of Social Psychiatry, 55, 99-108.

Rice, P., Rice, A., \& Dhamarak, P. (1993). Some day when my health is good. Youth Studies Australia, 12, 39-43.

Roberts, G. (2007, October 10). Siege mentality in a new country. Illawarra Mercury. Retrieved December 16, 2009, from: http://www.troublemakers.com.au/troublemakersarticles/2007/10/15/siege-mentality-in-a-new-country/

Sam, D.L., \& Berry, J.W. (2006). Contexts of acculturation. In J.W. Berry (Ed.), The Cambridge handbook of acculturation psychology (pp. 27-42). New York: Cambridge University Press.

Schweitzer, R., Melville, F., Steel, Z., \& Lacherez, P. (2006). Trauma, post-migration living difficulties, and social support as predictors of psychological adjustment in resettled Sudanese refugees. Australian and New Zealand Journal of Psychiatry, 40, 179-187.

Sonderegger, R., \& Barrett, P.M. (2004). Patterns of cultural adjustment among young migrants to Australia. Journal of Child and Family Studies, 13, 341-356.

Sonderegger, R., Barrett, P.M., \& Creed, P.A. (2004). Models of cultural adjustment for child and adolescent migrants to Australia: Internal process and situational factors. Journal of Child and Family Studies, 13, 357-371.

Steel, Z., Silove, D., Phan, T., \& Bauman, A. (2002). Long term effect of psychological trauma on the mental health of Vietnamese refugees resettled in Australia: A population based study. The Lancet, 360, 1056-1061.

Sudan Population. (2005). Retrieved 15 December 2009 from http://www.iss.co.za/af/profiles/Sudan/Population.html

Sudan Watch. (2006). Crises in Kakuma camp Kenya: UN reports alarming rates of malnutrition. November 2005. Retrieved December 15, 2009 from http://sudanwatch. blogspot.com/2006/01/crisis-in-kakuma-camp-kenyaun-reports.html

Sudan Watch. (2009). Retrieved December 15, 2009 from http://sudanwatch.blogspot.com/2009/05/population-ofsouth-sudan-826-million.html

Taha, H.E.M., \& De Mabior, G. (2005). Framework for sustained peace development and poverty eradication. Joint Assessment Mission Sudan United Nations Sudan Information Gateway. Retrieved September 12, 2006, from http://www. unsudanig.org/docs/joint

Taylor, T., \& Doherty, A. (2005). Adolescent sport, recreation and physical education: Experiences of recent arrivals to Canada. Sport, Education and Society, 10(2), 211-238.

Tempany, M. (2009). What research tells us about the mental health and on psychosocial wellbeing of Sudanese refugees: A literature review. Transcultural Psychiatry, 46(2), 300-315.

The Victorian Foundation for Survivors of Torture. (2005). Making a healthy start in Australia. Retrieved September 28, 2008, from http://www.foundationhouse.org.au 
Thlabano, K.N., \& Schweitzer, R. (2007). A qualitative study of the career aspirations of resettled young Sudanese and Somali refugees. Journal of Psychology in Africa, 17, 13-22.

Tong, V.M., Huang, C.W., \& McIntyre, T. (2006). Promoting a positive cross-cultural identity: Reaching immigrant students. Reclaiming Children and Youth, 14, 203-208.

United Nations Development Programme. (2008). Human Development Reports: 2007/2008 Reports: UNDP. Retrieved September 1, 2008, from http://hdrstats.undp.org/ countries/data_sheets/cty_ds_SDN.html

United Nations High Commissioner for Refugees. (1951). Text of the 1951 Convention relating to the status of refugees. Retrieved September 11, 2008, from http://www.unhcr.org/ protect/PROTECTION/3b66c2aa10.pdf
United Nations High Commission for Refugees. (2008). 2007 Global trends: Refugees, asylum seekers, returnees, internally displaced and stateless persons. Geneva: UNHCR. Retrieved September 1, 2008, from http//www.unhcr.org/statistics/ STATISTICS/4852366f2.pdf

$\mathrm{Vu}$ H.Q. (2008). Acculturation, intergenerational conflict and support, and psychological well-being. Dissertation Abstracts International: Section B: The Sciences and Engineering, 68(12-B), 8448.

Williams, C. L., \& Berry, J.W. (1991). Primary prevention of acculturation stress among refugees. American Psychologist, 46, 632-641.

Yakushko, O., Watson, M., \& Thompson, S. (2008). Stress and coping in the lives of recent immigrants and refugees: Considerations for counselling. International Journal of Advanced Counselling, 30, 167-178. 